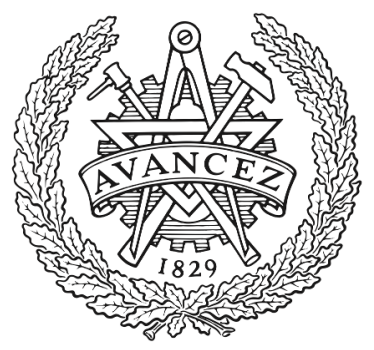

CHALMERS

UNIVERSITY OF TECHNOLOGY

\title{
Applying a set-based parametric design method to structural design of bridges
}

Downloaded from: https://research.chalmers.se, 2023-04-26 08:23 UTC

Citation for the original published paper (version of record):

Mathern, A., Rempling, R., Ramos, D. et al (2018). Applying a set-based parametric design method to structural design of bridges. IABSE Symposium, Nantes 2018: Tomorrow's Megastructures:

S5-215-S5-222-

N.B. When citing this work, cite the original published paper. 


\title{
Applying a set-based parametric design method to structural design of bridges
}

\author{
Alexandre Mathern, Rasmus Rempling
}

NCC Sverige AB / Chalmers University of Technology, Gothenburg, Sweden

\section{David Tarazona Ramos}

Volvo Cars, Gothenburg, Sweden

Santiago Luis Fernández

Grupo Cobra, Madrid, Spain

Contact: alexandre.mathern@chalmers.se

\begin{abstract}
Set-based design has been widely applied in manufacturing and product development, as it allows to consider a large number of alternatives during the design process. The design process in civil engineering projects may benefit from this alternative design approach, however its applicability in this field remains unexplored. The purpose of this study is to investigate the potential of applying a set-based parametric design method to the structural design of bridges. The method developed here combines set-based design, parametric design, finite element analysis and multi-criteria decision analysis. The developed method is applied to two existing bridges considering two sustainability criteria in the evaluation of the alternatives: material cost and carbon dioxide $\left(\mathrm{CO}_{2}\right)$ equivalent emissions. Preliminary results indicate that the method leads to bridges that are more efficient with regard to the selected sustainability criteria.
\end{abstract}

Keywords: Bridge, Structural Design, Set-Based Design, Parametric Design, Multi-Criteria

\section{Introduction}

Modern structural design faces new challenges such as addressing needs from several stakeholders and taking into account sustainability criteria. The traditional structural design process in civil engineering fails to address these challenges as it is almost exclusively based on a so-called pointbased design (PBD) approach. In this approach, the development of the design is based on an early choice of a preferred design solution followed by its sequential improvement, which means that many design alternatives are already discarded at an early stage.

The ineffectiveness of PBDs has motivated the development of alternative design approaches. Toyota was one of the first companies that started using a novel concept, based on parallel and delayed decision-making processes called setbased design [1]. In set-based design, the decisions involved in the design process are not made with a single alternative in mind; instead a set of alternatives is decided by the stakeholders and 
progressively narrowed down according to the requirements and choices of those involved in the project.

The purpose of this study was to investigate the potential of applying a set-based parametric design (SBPD) method in the early stage of structural design of bridges. Three main objectives were considered:

- Develop a well-defined method for the criteria-based design of bridges, while applying the principles of SBPD.

- Assess the applicability and potential of the method for different bridge design projects.

- Present an automated numerical method that performs the routine design tasks and generates information that can be used as a basis for making decisions in an integrated design process.

The framework for the proposed SBPD method includes the theories of integrated design proposed by the American Institute of Architects [2] and parametric design with regard to geometrical parameters.

Integrated design, which is closely related to the conceptual design proposed in [3], integrates different engineering disciplines and all stakeholders, while parametric design utilizes computer algorithms to consider variations of design parameters in an automated process.

Combining these two approaches may provide the construction community a cost-effective process to evaluate alternatives against common decided criteria, which address materials, structural system and member size.

\section{Method}

The applicability and potential of the proposed method were assessed by implementing an automated SBPD method for two common types of single-span bridges:

- a concrete beam bridge, and

- a steel-concrete composite bridge with integral abutments.

The method is based on the generation of numerous bridge alternatives by varying design parameters (e.g. dimensions, material properties, etc.) based on predefined ranges of variation.

The approach to automate the structural design process included the development of a script capable of performing the design tasks in the criteria design stage, as well as controlling the numerical analysis of the bridges. A flow chart of the script, developed in Python, is presented in Figure 1.

The computations were conducted on an AMD Opteron 6220 Linux cluster with 16 cores and $32 \mathrm{~GB}$ of RAM per node. The bridges corresponding to the different parameters combination were divided into a number of sets (i.e. $n$-sets). This allowed to run the calculations for the $n$-sets in parallel on a corresponding number of nodes (i.e. $n$-nodes) to reduce the computing time.

The bridges were analysed using the finite element software Abaqus/CAE 6.11-1. All the bridges were modelled entirely with shell elements, using general purpose shell elements (S4R) [4], to simplify the assembly between the different parts and the extraction of sectional forces for the design. 


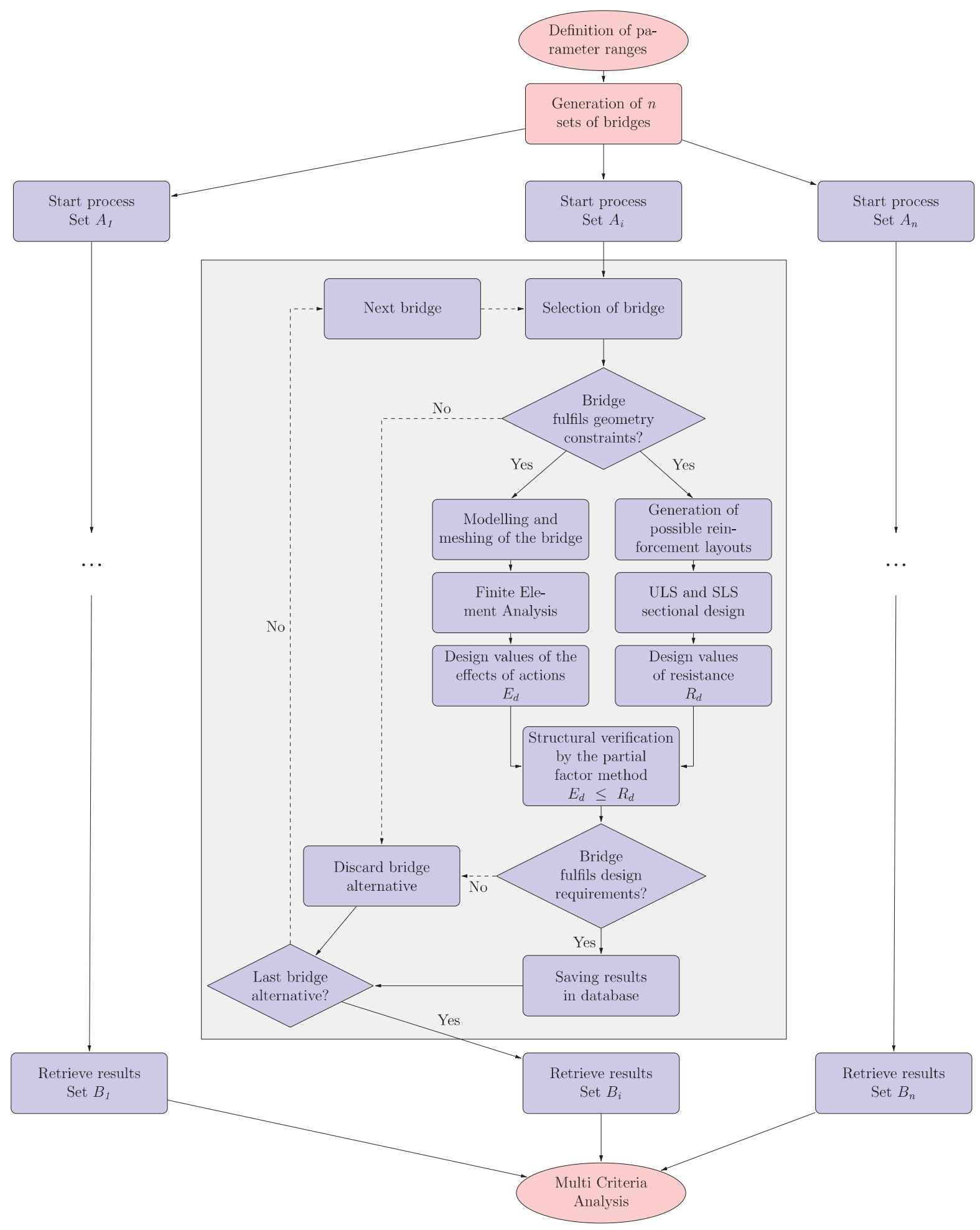

Figure 1. Flow chart of the Python script controlling the set-based parametric design method. 
Permanent loads and traffic loads were considered in the design process. The following methods were used to ensure consistency with the different bridge geometries considered. The self-weight of the bridges was introduced as a gravity load by defining the density of the materials. Traffic loads were introduced according to Load Model 1 of EN 1992-2:2005 [5].

As the preliminary design phase has been considered, simplifications have been adopted in the design of the concrete beams, steel girders and concrete decks:

- Fatigue has not been considered in the design.

- The shear connection between the steel girders and the concrete deck has not been considered and full composite action has been assumed in the design.

Ultimate limit state calculations were conducted to design the reinforcement in the concrete and check the capacity of the steel girders, according to the maximum sectional forces at different sections.

The sectional design of the concrete beams was performed by simple calculations, according to EN 1992-1-1:2004 [6], using the dimensional parameters defining the bridge. The beams are normally not reinforced homogeneously along the span owing to the variations in the shear force and bending moment distributions; therefore, different regions were considered.

The sectional design of the steel girders was performed according to EN 1994-1-1:2004 [7]. Lateral torsional buckling of the steel girders was checked in a simplified manner, during both the construction and the operation stage, according to [8].

For the design of the concrete decks, the maximum positive and negative moments were defined as the design values for all the longitudinal and transversal sections. These moments were combined with the corresponding torsional moment and membrane forces, when appropriate, to calculate the required reinforcement area.

Serviceability calculations were conducted to check the deflection and crack widths under the quasipermanent combination of loads. The deflection was defined as the maximum vertical displacement for all the load cases considered. This value was then compared with the standard limitation of $1 / 400$ of the theoretical span length, in accordance with the Swedish bridge design requirements [9]. Cracking was also checked, by taking into account the exposure class and limiting the crack widths to $w_{\max }$, according to EN 1992-2:2005 [5]. These checks were used to characterise a bridge as feasible or not.

Finally, a multi-criteria analysis was used to evaluate the sustainability of all the feasible bridges. In this study, the sustainability of the solution was assessed in a simplified manner by considering - for each material used - the cost, as well as the $\mathrm{CO}_{2}$ equivalent emissions (considering extraction, production and manufacturing) per weight of material.

\section{Case studies of the applicability of set-based parametric design in structural engineering}

In order to verify the applicability of the method, two existing bridges in Sweden were used for verification: a concrete beam bridge and a steel-concrete composite bridge with integral abutments. The design of these bridges was completed before this study was initiated, and the data used in this study was taken from the construction documents of the bridges.

The concrete beam bridge analysed in this study is situated in Örebro, and was built in 1996 (see Figure 2). It is a three-span road bridge crossing a double track railway. Only the superstructure of the central span of the bridge was considered in this study. This superstructure consists of a concrete deck resting on eight simply-supported concrete beams with a span length of $20 \mathrm{~m}$. 


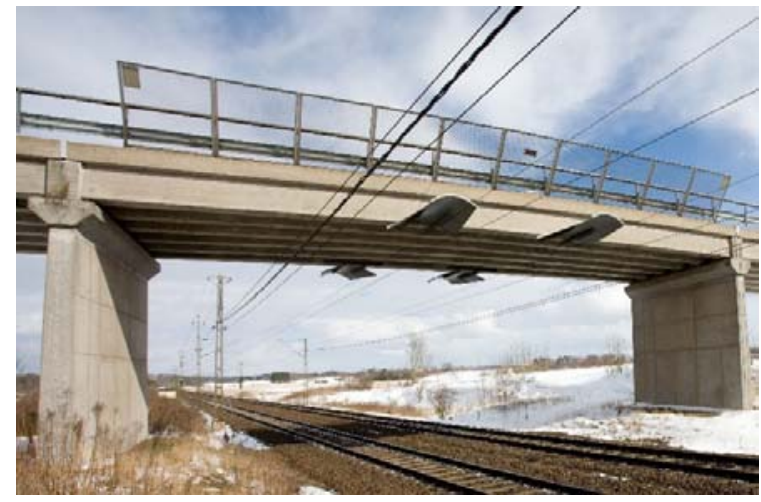

Figure 2: Concrete beam bridge investigated (source: NCC).

The steel-concrete composite bridge analysed in this study is situated in Nynäshamn, and was built in 2011 (see Figure 3). This single-span integral abutment bridge consists of two curved high strength stainless steel girders with a span length of $40 \mathrm{~m}$ and a concrete deck.

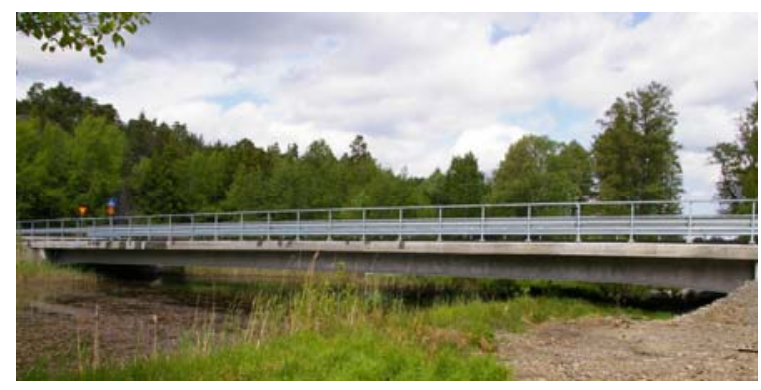

Figure 3: Steel-concrete composite bridge investigated (source: NCC).

The exposure class used for the design of both bridges was XC3.

A large number of alternatives were generated for each bridge by allowing the following parameters to vary within the specified ranges:

- thickness of the concrete deck,

- number of concrete beams or steel girders,

- height and width of the concrete beams or height and thickness of the web of the steel girders,

- thickness of the lower flange of the steel girders, and

- diameter of the longitudinal reinforcing bars in the concrete beams.

\section{Results}

The performed study resulted in the analysis of approximately 1100 concrete beam bridges (2500 taking into account the different reinforcement layouts considered) and 350 steel-concrete composite bridges. Figures 4 and 5 show the normalised material cost and $\mathrm{CO}_{2}$ equivalent emissions of the alternatives, respectively. The Figures also indicate the corresponding values for the existing bridges. The normalisation of the results was performed by dividing the material cost and the $\mathrm{CO}_{2}$ equivalent emissions by the minimum values obtained.

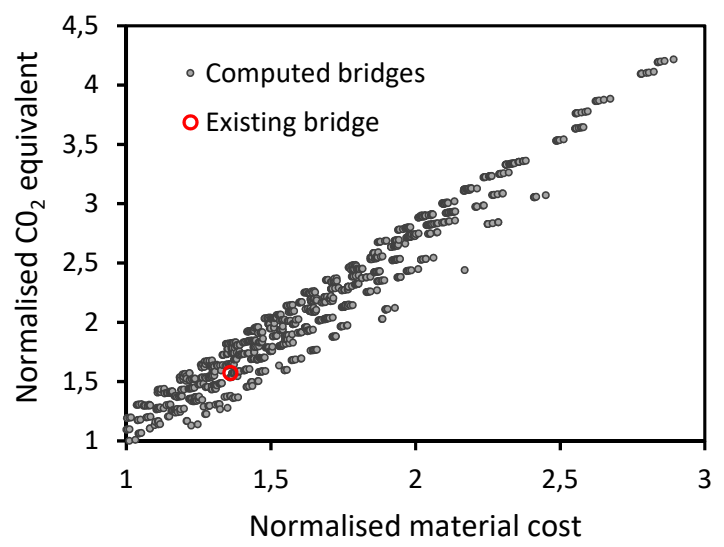

Figure 4: Estimated material cost and $\mathrm{CO}_{2}$ equivalent emissions for the concrete beam bridge.

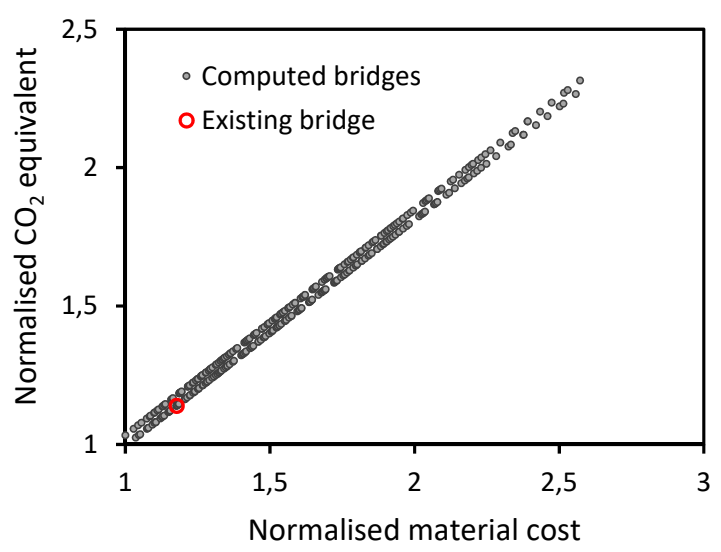

Figure 5: Estimated material cost and $\mathrm{CO}_{2}$ equivalent emissions for the steel-concrete composite bridge. 


\section{Discussion}

One objective of this study was to define a method for the preliminary design of structures, while applying the principles of SBPD. In this study, the concept of set-based design was based on predefined parameter ranges and generation of possible reinforcement layouts, i.e. numerous bridge alternatives were generated and various reinforcement layouts were added to these alternatives, an addition that generated sets of alternatives. This approach was used to evaluate the method using existing bridges. However, the method may similarly be applied to a real preliminary design scenario. Then, more parameters would be introduced and the sets of alternatives would be composed of different types of bridges, material combinations and/or building technologies that imply different construction methods. More criteria could also be introduced to narrow down the sets of alternatives (e.g. stakeholders' requirements) and to evaluate the remaining alternatives (e.g. construction time, buildability, life-cycle cost analysis, life-cycle assessment, etc.).

The applicability and potential of the method were assessed during the verification process. This assessment was made by choosing a range of parameters for each bridge. For the two different bridge scenarios, the number and type of parameters were similar - five for the concrete bridge and six for the steel-concrete composite bridge. However, the ranges of the variation were different, (e.g. four and three values for the width of the concrete beams and the web thickness of the steel girders respectively), which resulted in a larger or smaller number of alternatives. A consequence of this - that needs special attention in a real design scenario - is that a more optimised solution can be expected when considering a greater number of variations. However, it is not believed that this variation affected the verification or questioned the reliability of the proposed method.

The research shows that a key to a more effective design and construction is the automation of the routine design tasks $[10,11]$. The proposed method automates routine design tasks and the potential of this approach has been assessed to be very promising. As the development of a bridge concept includes a complete set of geometrical parameters, it is possible with a SBPD method to adjust the concept, and thereby, create a wider basis for the design decisions.

\section{Conclusion}

A method that integrates set-based design, parametric design, finite element analysis and multi-criteria decision analysis was proposed in this paper. This method performs the common design tasks and controls the numerical analysis as well as the multi-criteria analysis. Two existing bridges were used to verify the applicability of the method. It was shown that the set-based parametric design method proposed can be used to design a large number of alternative bridges and to evaluate them in terms of material cost and $\mathrm{CO}_{2}$ equivalent emissions. This method allows to design bridges that are more sustainable and cost-effective than with a traditional point-based design approach. This investigation advances the suitability and advantages of the proposed method for structural design of bridges.

\section{Acknowledgments}

The computations were performed on resources at Chalmers Centre for Computational Science and Engineering (C3SE) provided by the Swedish National Infrastructure for Computing (SNIC).

\section{References}

[1] Ward AC, Liker JK, Cristiano JJ, et al. The Second Toyota Paradox: How Delaying Decisions Can Make Better Cars Faster. Sloan Management Review, 1995, pp. 4361.

[2] AIA. Integrated Project Delivery: A Guide. 2007.

[3] CEB-fib. Bulletin 51: Structural Concrete Textbook on behaviour, design and performance. Second. Lausanne, Switzerland, 2009.

[4] Simulia. Abaqus 6.11 Theory Manual. 2011.

[5] CEN. EN 1992-2:2005. Eurocode 2 - Design of concrete structures - Part 2: Concrete 
bridges - Design and detailing rules. Brussels, 2005.

[6] CEN. EN 1992-1-1:2004. Eurocode 2: Design of concrete structures - Part 1-1: General rules and rules for buildings. Brussels, 2004.

[7] CEN. EN 1994-1-1:2004. Eurocode 4: Design of composite steel and concrete structures - Part 1-1: General rules and rules for buildings. Brussels, 2004.

[8] Bureau A. NCCI: Elastic critical moment for lateral torsional buckling. SNOO3a-EN-EU. 2005.

[9] Swedish Transport Administration. TDOK 2016:0204. [Requirements for bridge construction]. 2016. (in Swedish).

[10] Rempling R, Fall D, Lundgren K. Aspects of Integrated Design of Structures: Parametric Models, Creative Space and Linked Knowledge. Civ Eng Archit 2015; 3: 143152.

[11] Verhagen WJC, Bermell-Garcia P, van Dijk REC, et al. A critical review of KnowledgeBased Engineering: An identification of research challenges. Adv Eng Informatics 2012; 26: 5-15. 